\title{
ANALISIS FINANSIAL USAHA BUDIDAYA UDANG VANAME DI BALAI PELATIHAN DAN PENYULUHAN PERIKANAN (BPPP) AERTEMBAGA KOTA BITUNG PROVINSI SULAWESI UTARA
}

\author{
Lydia A. Wawoh'; Swenekhe S. Durand²; Grace 0. Tambani² \\ 1)Mahasiswa Fakultas Perikanan dan IImu Kelautan Universitas Sam Ratulangi Manado \\ 2)Staff Pengajar Fakultas Perikanan dan IImu Kelautan Universitas Sam Ratulangi Manado \\ Koresponden email : Iydiawawoh4@gmail.com
}

\begin{abstract}
The purpose of this study was to determine the process of vaname shrimp cultivation and to find out the financial analysis of the vaname shrimp farming business at the Fisheries Training and Extension Center (FTEC) Aertembaga Bitung City, North Sulawesi Province. The type of research used is a case study. Stake (2006) said that case studies are research methods that have important goals in researching and revealing the uniqueness and distinctiveness of characteristics found in the cases studied, where the case is the reason why the research was conducted. The vaname shrimp cultivation process consists of several stages, namely pool drying, pond washing, chlorine administration, probiotic administration, maintenance, feeding, harvesting, and post-harvest handling. The price of vaname shrimp at BPPP Aertembaga is Rp. $75,000 / \mathrm{Kg}$ with $800 \mathrm{~kg}$ of harvested shrimp. The total profit from the vaname shrimp cultivation business in 1 period is Rp. 120,000,000. Total cost for 1 period is Rp. 65,448,000 and total profit / net profit of Rp. $65,448,000$. So that the Profit Rate or the rate of profit obtained is $83.35 \%$ and Benefit Cost Ratio (BCR) is 1.83 with a repayment period of 1.7 years. The BEP Sales showed that the break-even point of the white shrimp farming business at BPPP Aertembaga was Rp. 17,745,461 and BEP units obtained were 236.60 $\mathrm{kg}$. Based on the results of its financial analysis, it turns out that the vaname shrimp farming in FTEC Aertembaga is feasible to be developed.
\end{abstract}

Key Words: Analysis of financial, business, vaname shrimp

\begin{abstract}
Abstrak
Tujuan dari penelitian ini untuk mengetahui proses budidaya udang vaname dan untuk mengetahui analisis finansial dari usaha budidaya udang vaname di Balai Pelatihan dan Penyuluhan Perikanan (BPPP) Aertembaga Kota Bitung Provinsi Sulawesi Utara. Jenis penelitian yang digunakan adalah studi kasus. Stake (2006) mengatakan studi kasus sebagai metode penelitian yang memiliki tujuan penting dalam meneliti dan mengungkap keunikan serta kekhasan karakteristik yang terdapat dalam kasus yang diteliti, dimana kasus tersebut menjadi penyebab mengapa penelitian dilakukan. Proses budidaya udang vaname terdiri dari beberapa tahap yakni penjemuran kolam, pencucian kolam, pemberian kaporit, pemberian probiotik, proses pemeliharaan, pemberian pakan, panen, dan penanganan pasca panen. Harga udang vaname di BPPP Aertembaga yaitu $\mathrm{Rp} .75 .000 / \mathrm{Kg}$ dengan hasil udang yang di panen sebanyak $800 \mathrm{~kg}$. Total keuntungan dari usaha budidaya udang vaname dalam 1 periode sebesar Rp.120.000.000. Total cost selama 1 periode sebesar Rp. 65.448 .000 dan Total keuntungan / Net Profit sebesar Rp. 65.448.000. Sehingga Profit Rate atau tingkat keuntungan yang diperoleh sebesar 83,35\% dan Benefit Cost Ratio (BCR) adalah 1,83 dengan jangka waktu pengembalian 1,7 tahun. BEP Penjualan menunjukkan bahwa titik impas dari usaha budidaya udang vaname di BPPP Aertembaga adalah Rp. 17.745.461 dan BEP satuan yang didapat yaitu 236,60 $\mathrm{kg}$. Berdasarkan hasil analisis finansialnya ternyata usaha budidaya udang vaname di BPPP Aertembaga layak untuk dikembangkan.
\end{abstract}

Kata Kunci: Analisis finansial, usaha, udang vaname

\section{PENDAHULUAN}

Indonesia memiliki potensi Sumber Daya Alam (SDA) kelautan terbentang luas di bumi nusantara yang merupakan potensi besar Negara Indonesia. Kondisi tersebut merupakan aset yang sangat mahal dan sekaligus sebagai faktor keunggulan kompetitif yang tidak dimiliki oleh negaranegara lain. Potensi sumber daya alam kelautan tersebut merupakan faktor dominan dalam strategi pembangunan Bangsa dan
Negara Indonesia terutama dalam menghadapi era globalisasi dan perdagangan bebas. Kementerian Kelautan dan Perikanan (KKP) telah menetapkan tiga kebijakan pokok pembangunan kelautan dan perikanan tahun 2015-2019 sebagai kerangka dalam mewujudkan Indonesia sebagai poros maritim dunia, satu diantaranya adalah menerapkan prinsipprinsip pengelolaan sumberdaya kelautan dan perikanan yang bertanggung jawab, 
berdaya saing, dan berkelanjutan (KKP, 2015).

Balai Pelatihan dan Penyuluhan Perikanan (BPPP) Aertembaga sebagai salah satu lembaga fungsional kediklatan, merupakan Unit Pelaksana Teknis Kediklatan di bawah Badan Pengembangan SDM Kelautan dan Perikanan Kementerian Kelautan dan Perikanan yang mempunyai tugas pokok "Melaksanakan bimbingan serta pelatihan teknis dan manajerial perikanan", pelatihan kepelautan bagi awak kapal penangkap ikan adalah salah satu pelatihan yang ada di BPPP Aertembaga Bitung. BPPP Aertembaga juga melaksanakan pelatihan budidaya ikan yang meliputi usaha budidaya, pengembangan produksi, pembenihan dan pemasaran.

Budidaya udang merupakan prospek usaha yang menjanjikan. Budidaya udang vaname adalah salah satu kegiatan yang dilaksanakan oleh BPPP Aertembaga dan budidaya udang vaname di BPPP Aertembaga juga dipasarkan. Usaha budidaya udang vaname di BPPP Aertembaga sudah berjalan sejak Tahun 2016, waktu pembudidayaannya 3-4 bulan per siklus, udang juga lebih tahan penyakit, bahkan usaha budidaya udang vaname yang ada di BPPP Aertembaga ini belum pernah terserang hama ataupun penyakit sehingga banyak konsumen baik dalam kota maupun dari luar kota yang tertarik dan membeli udang vaname yang ada di BPPP Aertembaga. Adapun usaha budidaya udang vaname di BPPP Aertembaga belum dilakukan perhitungan analisis finansialnya. Dengan adanya kegiatan usaha budidaya udang vaname yang ada di BPPP Aertembaga ini, peneliti tertarik untuk melakukan penelitian tentang analisis finansial usaha budiaya udang vaname di BPPP Aertembaga.

\section{METODE PENELITIAN}

Jenis penelitian yang digunakan adalah studi kasus. Stake (2006) mengatakan studi kasus sebagai metode penelitian yang memiliki tujuan penting dalam meneliti dan mengungkap keunikan serta kekhasan karakteristik yang terdapat dalam kasus yang diteliti, dimana kasus tersebut menjadi penyebab mengapa penelitian dilakukan.

Data primer didapat dari sumber informan yaitu Bapak Ronal Malingkas yang merupakan salah satu teknisi di bidang pembudidayaan dan menjabat sebagai Koordinator Widyaswara di BPPP Aertembaga dan juga tiga teknisi di bidang pembudidayaan Fiqi (27 tahun), Gani (35 tahun) dan Herry (35 tahun), sebagaimana hasil wawancara yang telah dilakukan oleh peneliti. Data primer ini didapat melalui;

1. Hasil observasi lapangan.

2. Catatan hasil wawancara.

Data sekunder adalah data yang diperoleh melalui data yang ada di Balai Pelatihan dan Penyuluhan Perikanan (BPPP) Aertembaga Kota Bitung dan studi pustaka.

Variabel-variabel yang diukur dalam penelitian ini adalah:

1. Produksi, yaitu produksi budidaya udang selama 1 tahun

2. Penerimaan total dari produksi selama 1 tahun dihitung dalam kilogram dan rupiah

3. Biaya tetap selama 1 tahun dihitung dalam rupiah

4. Biaya tidak tetap selama 1 tahun dihitung dalam rupiah

5. Biaya total selama 1 tahun dihitung dalam rupiah

6. Keuntungan, yaitu penerimaan total dikurangi biaya total yang dikeluarkan selama 1 tahun dihitung dalam rupiah

7. Harga jual $(\mathrm{Rp} / \mathrm{Kg})$

Menurut Kadariah (1995), untuk mengetahui keuntungan budidaya udang 
vaname digunakan analisis finansial dengan menggunakan formula :

1. Opertion Profit, yaitu keuntungan usaha budidaya udang vaname yang merupakan selisih antara pendapatan kotor dengan biaya tidak tetap.

$$
O P=T R-V C
$$

Dimana: OP = Keuntungan

usaha budidaya udang vaname

$\mathrm{TR}=$ Total Revenue

$\mathrm{VC}=$ Variabel Cost

2. Net Profit, yaitu keuntungan absolut yang merupakan selisih antara seluruh penerimaan atau hasil penjualan dengan seluruh pengeluaran.

$$
\pi=T R-T C
$$

Dimana : $\pi=$ Net Profit/total keuntungan

$\mathrm{TR}=$ Total Revanue

$\mathrm{TC}=$ Total Cost

3. Profit Rate, yaitu keuntungan yang menunjukkan kemampuan suatu usaha dalam memberikan keuntungan jika dibandingkan dengan jumlah keseluruhan biaya yang dikeluarkan.

$$
\frac{\pi}{T C} X 100 \%
$$

Dimana: $\pi=$ Net Profit $/$ total keuntungan

$$
\mathrm{TC}=\text { Total Cost }
$$

4. Benefit Cost Ratio, yaitu suatu analisis yang diperlukan untuk melihat sejauh mana perbandingan antara nilai manfaat terhadap nilai biaya dilihat pada kondisi nilai sekarang. Apabila $B C R$ >1 maka usaha tersebut layak dijalankan.

$$
B C R=\frac{\text { Hasil Penjulan }}{\text { Biaya Total }}
$$

5. Rentabilitas, yaitu rasio keuntungan bersih dengan investasi dalam suatu unit usaha.

$$
\frac{\pi}{I} \times 100 \%
$$

Dimana : $\pi=$ Net Profit $/$ total keuntungan

$$
\text { I = Investasi }
$$

6. Break Event Point, yaitu titik pulang pokok.
a. BEP Penjualan $=\frac{F C}{1-\frac{V C}{T R}}$
b. BEP Satuan = hasil penjualan

Dimana : $F C=$ Fixed Cost

$\mathrm{VC}=$ Variabel Cost

$\mathrm{TR}=$ Total Revanue

7. Jangka waktu pengembalian

$$
\frac{T C}{\pi} \times n \text { tahun }
$$

Dimana : $\mathrm{TC}=$ Total Cost

$\pi=$ NetProfittotal keuntungan

\section{HASIL DAN PEMBAHASAN}

\section{Faktor-faktor Produksi Budidaya Udang} Vaname

\section{Benih Udang Vaname}

Benih udang vaname yang ditebar berasal dari perusahaan dari Hatchery Benur Kita yang ada di Sulawesi Selatan. Umumnya Hatch ery menjual benih udang vaname pada PL (post Larva) 10-12. Benih udang vaname yang diperlukan dalam 1 kali periode sebanyak 66.000 ekor. Harga benih udang vaname yang ada di hatchery Benur Kita adalah Rp. 60/ekor.

\section{Pakan Udang}

Pakan udang sangat berperan penting untuk peningkatan jumlah produksi udang vaname yang ditebarkan di kolam BPPP Aertembaga. Apabila makanan yang diberikan tidak cukup maka produksi yang dihasilkan pasti hanya sedikit, karena makanan mempunyai peranan penting bagi pertumbuhan udang, maka pemberian makanan harus benar-benar diperhatikan.

Untuk harga pakan yang digunakan adalah Rp.18.500/kilogram. Sedangkan pakan yang dibutuhkan dalam 1 kali periode sebanyak 1 ton untuk target $800 \mathrm{~kg}$ udang. Jenis Pakan yang digunakan adalah Vannamei Shrimp Feeed yang dibeli dari PT. CJ FEED JOMBANG di Jawa Timur. 


\section{Struktur Biaya}

Biaya merupakan faktor yang menjadi dasar penetapan harga jual yang diterapkan pada produk. Perusahaan menginginkan agar harga yang ditetapkan dapat mencakup semua biaya untuk memproduksi, mendistribusikan, dan menjual produk serta tingkat laba yang sesuai dengan upaya yang dilakukan dan resiko yang dihadapi. Biaya merupakan elemen penting dalam penetapan strategi harga (Machfoedz, 2005).

Untuk melakukan usaha budidaya udang vaname, pelaku usaha dapat mencari tahu dan menyediakan modal investasi dan juga pelaku usaha menyediakan biaya-biaya lain seperti biaya tetap dan biaya tidak tetap.

Suroto (2000), mengatakan pendapatan adalah seluruh penerimaan baik berupa uang maupun berupa barang yang berasal dari pihak lain maupun hasil industri yang dinilai atas dasar sejumlah uang dari harta yang berlaku saat itu. Pendapatan merupakan sumber penghasilan seseorang untuk memenuhi kebutuhan sehari - hari dan sangat penting artinya bagi kelangsungan hidup dan penghidupan seseorang secara langsung mau pun tidak lagsung

\section{Investasi}

Dalam menjalankan suatu usaha hal yang sangat penting yang harus disediakan dan dan dilakukan oleh pelaku usaha adalah modal. Modal merupakan dana awal dan pembentukan suatu usaha. Untuk lebih jelasnya modal investasi dari usaha budidaya udang vaname dapat dilihat pada tabel 04.

Tabel 01. Modal Investasi Usaha

\begin{tabular}{|c|c|c|c|c|}
\hline No & Nama Alat & $\begin{array}{c}\text { Harga Satuan } \\
\text { (Rp) }\end{array}$ & $\begin{array}{c}\text { Jumlah } \\
\text { Yang } \\
\text { diperlukan }\end{array}$ & $\begin{array}{l}\text { Jumlah Biaya } \\
\text { (Rp) }\end{array}$ \\
\hline 1. & Jaring Waring & 9000 & 210 meter & 1.890 .000 \\
\hline 2. & Kincir & 5.000 .000 & 2 unit & 10.000 .000 \\
\hline 3. & Blower (besar) & (3) $\quad 7.000 .000$ & 1 unit & 7.000 .000 \\
\hline 4. & Genset & 15.000 .000 & 1 unit & 15.000 .000 \\
\hline 5. & Jaring (monofilament) & 150.000 & 3 jaring & 450.000 \\
\hline 6. & and & 27.000 & 400 meter & 10.800 .000 \\
\hline 7. & Pipa merk AW, 4 inch & 67.450 & 150 meter & 10.117 .500 \\
\hline 8. & Tali PE & 50.000 & 1 kilo & 50.000 \\
\hline 9. & Keranjang & 95.000 & 2 unit & 190.000 \\
\hline 10. & Cool box & 35.000 & 5 unit & 175.000 \\
\hline 11. & Pompa Air Tawar & 3.000 .000 & 1 unit & 3.000 .000 \\
\hline 12. & Alat pengukur kualitas air $(\mathrm{pH})$ & 400.000 & 1 unit & 400.000 \\
\hline 13. & Timbangan $\mathrm{C}$ & 153.000 & 1 unit & 153.000 \\
\hline 14. & Ember pakan (80 liter) & 150.000 & 2 unit & 300.000 \\
\hline 15. & Pompa Air Laut & 30.000 .000 & 1 unit & 30.000 .000 \\
\hline 16. & Alat Pengukur Suhu & 50.000 & 1 unit & 50.000 \\
\hline 17. & Alat Pengukur Fracto (Sanilitas) & 2.500 .000 & 1 unit & 2.500 .000 \\
\hline 18. & Alat Pengukur Ph (kertas lakmus) & 210.000 & 1 unit & 210.000 \\
\hline 19. & Alat Pengukur Ph (Meter) & 450.000 & 1 unit & 450.000 \\
\hline 20. & Piring sesi & 30.000 & 1 unit & 30.000 \\
\hline \multicolumn{4}{|c|}{ Total } & 92.765 .500 \\
\hline
\end{tabular}

Sumber: Data Primer BPPP Aertembaga 2019

Dalam tabel 04 menunjukkan bahwa modal investasi yang dibutuhkan untuk usaha perikanan seperti pada usaha budidaya udang vaname di BPPP
Aertembaga dibutuhkan modal sekitar Rp. 92.765 .500 


\section{Biaya Tetap (Fixed Cost)}

Biaya tetap (fixed cost) adalah biaya yang tidak berubah selama proses produksi berlangsung, merupakan jenis biaya yang bersifat statis (tidak berubah) dalam ukuran tertentu. (Ibrahim 2003)

Biaya ini akan tetap dikeluarkan meskipun tidak melakukan aktivitas apapun. Untuk biaya tetap yang dikeluarkan pada usaha budiaya udang vaname di BPPP Aertembaga dapat dilihat pada tabel 05 .

Tabel 02. Biaya Tetap (Fix Cost) per tahun

\begin{tabular}{|c|c|c|}
\hline No. & Biaya Tetap & $\begin{array}{c}\text { Jumlah Biaya } \\
(R p)\end{array}$ \\
\hline 1. & Perawatan mesin kincir (kipas) 2 unit / tahun & 6.000 .000 \\
\hline 2. & Ganti oli mesin kincir 2x35.0000 / tahun & 70.000 \\
\hline 3. & Perawatan pompa air laut $2 \times 400.000 /$ tahun & 800.000 \\
\hline 4. & Perawatan jaring $1 \times 35.000 /$ tahun & 35.000 \\
\hline 5. & Perawatan terpal $2 \times 45.000 /$ tahun & 90.000 \\
\hline 6. & Penyusutan kincir (5 tahun) $1 / 5 \times$ Rp. $5.000 .000 \times 2$ unit & 2.000 .000 \\
\hline 7. & Penyusutan Blower (5 tahun) 1/5 x Rp. 7.000 .000 & 1.400 .000 \\
\hline 8. & Penyusutan Pompa Air laut (10 tahun) 1/10 Rp. 30.000 .000 & 3.000 .000 \\
\hline 9. & Penyusutan terpal (15 tahun) $1 / 15 \times 10.800 .000$ & 720.000 \\
\hline & Total Biaya Tetap & 14.115 .000 \\
\hline
\end{tabular}

Sumber: Data Primer BPPP Aertembaga 2019

Dalam tabel 05 menunjukkan bahwa biaya tetap atau biaya perawatan pada usaha budidaya udang vaname di BPPP Aertembaga dalam jangka waktu 1 tahun adalah sekitar Rp.14.115.000,-

\section{Biaya Tidak Tetap (Variable Cost)}

Biaya tidak tetap (variable cost) merupakan biaya yang berubah sepanjang proses produksi berlangsung, jenis biaya ini difungsikan untuk melengkapi biaya tetap dan bersifat dinamis. Biaya ini mengikuti banyaknya jumlah unit yang diproduksi ataupun banyaknya aktivitas yang dilakukan. Untuk biaya tidak tetap yang dikeluarkan pada usaha budidaya udang vaname di BPPP Aertembaga dapat dilihat pada Tabel 06.

Tabel 03. Biaya Tidak Tetap (Variable Cost) per tahun

\begin{tabular}{|c|c|c|}
\hline No. & $\begin{array}{c}\text { Biaya Tidak Tetap } \\
\text { (Operasional) }\end{array}$ & $\begin{array}{l}\text { Jumlah Biaya } \\
\text { (Rp) }\end{array}$ \\
\hline 1. & Benih Udang 66.000 ekor $\times 2$ periode $\times$ Rp. 60 & 7.920 .000 \\
\hline 2. & Es balok $5 \times 2$ periode $\times$ Rp. 18.000 & 180.000 \\
\hline 3. & Kantong kresek ( 5 liter) 2 pak $\times 2$ periode $\times$ Rp. 10.000 & 40.000 \\
\hline 4. & Pakan 1 ton $\times 2$ periode $\times$ Rp. $18.500 / \mathrm{kg}$ & 37.000 .000 \\
\hline 5. & Kapur 2 sak $(20 \mathrm{~kg}) \times 2$ periode $\times$ Rp.2000/kg & 80.000 \\
\hline 6. & Super $\mathrm{Nb} 1$ jergen (5 liter) & 450.000 \\
\hline 7. & Molase 20 liter & 375.000 \\
\hline 8. & Ragi Fermipan 500 gram & 40.000 \\
\hline 9. & Tenaga Kerja 4 orang & 5.248 .000 \\
\hline & Total Biaya Tidak Tetap & 51.333 .000 \\
\hline
\end{tabular}

Sumber: Data Primer BPPP Aertembaga 2019

Dalam tabel 06 menunjukkan bahwa biaya tidak tetap atau biaya operasional yang di keluarkan dalam usaha budidaya udang vaname di BPPP Aertembaga dalam jangka waktu 1 tahun adalah sekitar Rp. 51.333.000

\section{Pemasaran / Penjualan}

Wilayah pemasaran udang vaname berada di dalam dan di luar Kota Bitung. Dalam proses pemasaran usaha budidaya udang vaname di BPPP Aertembaga hanya menggunakan sosial 
media online dan juga lewat pesan melalui telepon genggam yang disampaikan dari produsen kepada konsumen seperti pemilik rumah makan dan hotel. Berdasarkan hasil penelitian yang dilakukan di BPPP Aertembaga, harga udang vaname adalah $\mathrm{Rp}$. 75.000 ,-/kilogram. Dalam 1 kali periode udang yang dihasilkan sebanyak 800 kilogram, untuk pemasaran / penjualan udang vaname di BPPP Aertembaga dilakukan dengan perhitungan sebagai berikut:

$800 \mathrm{~kg} \times 2$ periode $\times$ Rp. 75.000,- = Rp.120.000.000

Analisis Finansial Usaha Budidaya Udang Vaname di BPPP Aertembaga

Untuk dapat mengetahui jangka panjang waktu pengembalian modal maka dapat dilihat di bawah ini :

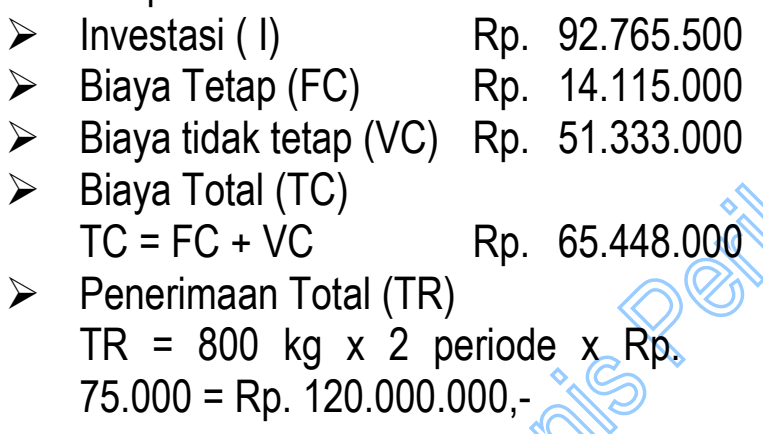

\section{Penerimaan / Operating Profit (OP)}

Operating profit (OP) yaitu keuntungan usaha budiaya udang yang merupakan selisih antara pendapatan kotor dengan biaya tidak tetap. Rumus yang digunakan untuk menghitung besarnya Operating Profit (OP) pada usaha ini yaitu:

$$
\begin{aligned}
\mathrm{OP} & =\mathrm{TR}-\mathrm{VC} \\
& =120.000 .000-51.333 .000 \\
& =68.667 .000
\end{aligned}
$$

Operating Profit (OP) dari usaha ini sebesar Rp.68.667.000 merupakan keuntungan yang diperoleh dan dapat digunakan untuk biaya produksi berikutnya.
Net Profit / total keuntungan

Keuntungan usaha budidaya udang vaname di BPPP Aertembaga dapat di rumuskan sebagai berikut :

$$
\begin{aligned}
\pi \quad & =\mathrm{TR}-\mathrm{TC} \\
& =120.000 .000-65.448 .000 \\
& =65.448 .000
\end{aligned}
$$

Net Profit atau total keuntungan yang didapat pada usaha budidaya udang vaname di BPPP Aertembaga sebesar Rp. 54.552.000

\section{Profit Rate / tingkat keuntungan}

Keuntungan yang menunjukkan kemampuan suatu usaha dalam memberikan keuntungan jika dibandingkan dengan jumlah keseluruhan biaya yang dikeluarkan.

$\frac{\pi}{T C} \times 100$

$\frac{54.552 .000}{65.448 .000} \times 100=83,35 \%$

Reuntungan yang diperoleh sebesar $83,35 \%$ sehingga usaha budidaya udang vaname di BPPP Aertembaga yang dijalankan mengalami keuntungan.

\section{Rentabilitas}

Rentabilitas yaitu ratio keuntungan bersih dengan investasi dalam satu unit usaha. Untuk mengetahui rentabilitas usaha budidaya udang vaname di BPPP Aertembaga dapat di hitung dengan menggunakan rumus :

$\frac{\pi}{I} x 100$

$$
\begin{aligned}
& \frac{54.552 .000}{92.765 .500} \times 100=58,80 \% \\
& \text { Jadi, rentabilitas yaitu ratio } \\
& \text { keuntungan bersih dengan investasi dari } \\
& \text { usaha budidaya udang vaname dalam } \\
& \text { satu unit usaha yaitu 58,80\%. }
\end{aligned}
$$

\subsection{2 .000}




\section{Analisis Imbangan / Benefit Cost Ratio (BCR)}

Benefit Cost Ratio (BCR) yaitu perkiraan manfaat yang diharapkan pada waktu mendatang atau ratio penerimaan dengan seluruh pengeluaran. Apabila $\mathrm{BCR}>1$ maka usaha tersebut layak dijalankan.

$$
\begin{aligned}
& B C R=\frac{T R}{T C} \\
& B C R=\frac{120.000 .000}{65.448 .000}=1,83
\end{aligned}
$$

Usaha budidaya udang vaname di BPPP Aertembaga layak untuk dijalankan karena memiliki nilai BCR yaitu 1,83.

\section{Jangka Waktu Pengembalian}

Analisis jangka waktu pengembalian / pacyback period (PP) bertujuan untuk mengetahui tingkat pengembalian investasi yang telah ditanamkan pada suatu usaha. Untuk mengetahui jangka waktu pengembalian payback period (PP) investasi pada usaha budidaya udang vaname di BPPP Aertembaga yaitu dengan cara melakukan perhitungan sebagai berikut:

\subsection{5 .500 \\ $\frac{54.552 .000}{X 1} 1$ tomun $=1,7$ tahun}

Biaya investasi yang dikeluarkan untuk usaha budidaya udang vaname di BPPP Aertembaga akan kembali dalam jangka waktu 1,7 tahun.

\section{Break Event Point (BEP)}

Break Event Point (BEP), merupakan parameter analisis yang digunakan untuk mengetahui batas nilai produksi pada usaha budidaya udang vaname di BPPP Aertembaga mencapai titik impas, yaitu tidak untung atau tidak rugi. Pada keadaan ini keuntungan atau kerugian sama dengan nol. Nilai BEP (penjualan) dan nilai BEP (satuan) pada usaha budidaya udang vaname di BPPP Aertembaga.

1. $B E P($ Penjualan $)=\frac{F C}{1-\frac{V C}{T R}}$ $=\frac{14.115 .000}{1-\frac{51.333 .000}{120.000 .000}}$ $=\frac{14 \cdot 115 \cdot 000}{1-0,43}$ $=\frac{10.115 \cdot 000}{0,57}$ $=\operatorname{Rp} \bigwedge 7.745 .461$

2. $B E P$ (Satuan) = BEP penjualan hargasatuan $(\mathrm{kg})$ $=\frac{17.745 .461}{75.000 /(\mathrm{kg})}$ $=236,60 \mathrm{~kg}$

Berdasarkan analisis yang diperoleh dari BEP Penjualan menunjukkan bahwa titik impas dari usaha budidaya udang vaname di BPPP Aertembaga adalah Rp. 17.745.461dan BEP satuan yang didapat yaitu 236,60 $\mathrm{kg}$.

\section{KESIMPULAN}

Pemeliharaan udang vaname yang ada di BPPP Aertembaga Kota Bitung dilakukan pada 2 buah kolam. Ukuran 2 buah kolam tersebut $400 \mathrm{~m}^{2}$, tinggi kolam $1 \mathrm{~m}$ dan $1,5 \mathrm{~m}$ yang berbentuk persegi empat. Pembesaran budidaya udang vaname yang pertama adalah penjemuran kolam, pencucian kolam, pemberian kaporit, pemberian probiotik, proses pemeliharaan, pemberian pakan, panen, dan penanganan pasca panen.

Harga udang vaname di BPPP Aertembaga yaitu Rp. $75.000 / \mathrm{Kg}$ dengan hasil udang yang dipanen sebanyak $800 \mathrm{~kg}$. Total keuntungan dari usaha budidaya udang vaname dalam 1 periode sebesar Rp.120.000.000. Total cost selama 1 periode sebesar Rp. 65.448.000 dan Total keuntungan / Net 
Profit sebesar Rp65.448.000. Sehingga Profit Rate atau tingkat keuntungan yang

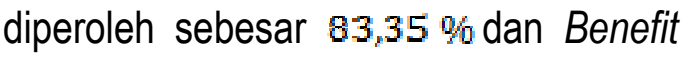
Cost Ratio $(B C R)$ adalah 1,83 dengan jangka waktu pengembalian 1,7 tahun. BEP Penjualan menunjukkan bahwa titik impas dari usaha budidaya udang vaname di BPPP Aertembaga adalah Rp17.745.461 dan BEP satuan yang didapat yaitu $236,60 \mathrm{~kg}$. Berdasarkan hasil analisis finansialnya ternyata usaha budidaya dang vaname di BPPP Aertembaga layak untuk dikembangkan.

\section{DAFTAR PUSTAKA}

Abdurrahmat, Fathoni. 2006. Metodologi Penelitian \& Teknik Penyusunan Skripsi. Jakarta: PT. Rineka Cipta.

Alikodra, HS. 2005. Konsep Pengelolaan Wilayah Pesisir Secara Terpadu dan Berkelanjutan. NTB.

Briggs M, Simon FS., R. Subasinghe and M. Phillips. 2004. Introduction and Movement of Penaeus vannamei and Penaeus stylirostris in Asia and Pasific. FAO UN, Bangkok

Effendi, I., 2004. Pengantar Akuakultur. Depok: Penebar Swadaya.

Esterberg \& Sugiyono. 2006. Metode Penelitian Kuantitatif Kualitatif dan R\&D. Bandung: Alfabeta.

Fathoni, Abdurrahmat. 2006. Organisasi Dan Manajemen Sumber Daya Manusia. Jakarta: PT Rineka Cipta.

Haliman, RW. dan D. Adijaya. 2005. Pembudidayaan dan Prospek Pasar Udang Vaname yang Tahan Penyakit. Penebar Swadaya. Jakarta.

Husein, Umar, 2009. Studi Kelayakan Bisnis. Gramedia Pustaka Utama, Jakarta.

Husnan, S dan S. Muhammad.2000. Studi Kelayakan Proyek. UPP. AMP.YKPN. Yogyakarta.

Ibrahim, Y. 2003. Studi Kelayakan Bisnis. Rineka Cipta. Jakarta.
Kadariah. 2001. Evaluasi Proyek Analisis Ekonomi. Lembaga Penerbit Fakultas Ekonomi Universitas Indonesia. Jakarta.

Kordi, K.M.G.H. 2010. Budidaya Udang Air Payaut. Lily Publisher. Yogyakarta.

Machfoedz, Mahmud. 2005. Pengantar Pemasaran Modern. Yogyakarta: UPP AMP YKPN.

Menristek. 2003. Budidaya Udang Windu. http://warintekbantul.com.

Nuhman. 2008. Pengaruh Prosentase Pemberian Pakan terhadap Kelangsungan Hidup dan Laju Pertumbuhan Udang Vannamei (Litopenaeus vannamei). Jurnal IImiah Perikanan dan Kelautan. Surabaya: Universitas Hang Tuah.

Riani. 2012. Efek Pengurangan Pakan terhadapPertumbuhan Udang Vaname (Lithopenaeus Vannamei) PL-21 yang diberi Bioflok. Fakultas Perikanan dan IImu Kelautan Unpad. Bandung.

Riduwan. 2004. Metode dan Teknik Menyusun Tesis. Cetakan Pertama. Bandung: Alfabeta.

Sekaran, Uma. 2011. Metode Penelitian Untuk Bisnis. Jakarta: Salemba, Empat.

Sjarkowi, F dan M. Sufri. 2004. Manajemen Agribisnis. Baldal Grafiti Press. Palembang.

Soekartawi. 2001. Pengantar Agroindustri. Edisi 1. Jakarta: Cetakan 2. PT Raja Grafindo Persada.

Subana, Sudrajat. 2005. Dasar-Dasar Penelitian IImiah. Bandung: Pustaka Setia.

Sugiyono. 2010. Metode Penelitian Kuantitatif Kualitatif dan R\&D. Alfabeta. Bandung.

Sugiyono. 2010. Metode Penelitian Pendidikan. Bandung: Alfabeta.

Suliyanto. 2006. Metode Riset Bisnis. Yogyakarta: Andi.

Supardi. 2006. Metode Penelitian. Mataram: Yayasan Cerdas Press.

Suroto. 2000. Strategi pembangunan dan Perencanaan Perencanaan Kesempatan Kerja. Yogyakarta: Gajah Mada Univercity.

Uma Sekaran. 2003. Research Methods for Bussiness. Jakarta: Salemba Empat.

Widi. 2010. Asas Metodologi Penelitian. Yogyakarta: Graha IImu. 